\title{
Quasi-Solid-State Polymer Electrolytes Based on a Polymeric Ionic Liquid with High Ionic Conductivity and Enhanced Stability
}

\author{
Nawon Jeon, Sung-Geun Jo, Sang-Hyung Kim, Myung-Soo Park, and Dong-Won Kim* \\ Department of Chemical Engineering, Hanyang University, Seungdong-Gu, Seoul 133-791, Republic of Korea
}

\begin{abstract}
A polymeric ionic liquid, poly(1-methyl 3-(2-acryloyloxypropyl) imidazolium iodide) (PMAPII), was synthesized as a single-iodide-ion-conducting polymer and employed in a gel polymer electrolyte. Gel polymer electrolytes prepared from iodine, 4-tert-butylpyridine, $\gamma$-butyrolactone, and PMAPII were applied in quasi-solid-state dye-sensitized solar cells (DSSCs). The addition of $16 \mathrm{wt. \%}$ PMAPII provided the most favorable environment, striking a compromise between the iodide ion concentration and the ionic mobility, which resulted in the highest conversion efficiency of the resulting DSSCs. The quasi-solid-state DSSC assembled with the optimized gel polymer electrolyte exhibited a relatively high conversion efficiency of $7.67 \%$ under AM 1.5 illumination at $100 \mathrm{~mA} \mathrm{~cm}^{-2}$ and better stability than that of the DSSC with a liquid electrolyte.
\end{abstract}

Keywords : Dye-sensitized solar cell, Gel polymer electrolyte, Polymeric ionic liquid, Single-ion conductor

Received : 26 July 2017, Accepted : 10 September 2017

\section{Introduction}

Since O'Regan and Gratzel's first report of a dyesensitized solar cell (DSSC) in 1991, DSSCs have attracted a great deal of attention as a potential replacement for conventional silicon solar cells because of their low cost, ease of fabrication, and relatively high conversion efficiency [1-5]. However, the potential problems caused by the liquid electrolytes, such as the leakage or evaporation of the organic solvent, are considered critical problems that limit the long-term operation and large-scale production of DSSCs. To overcome these problems, considerable efforts have been devoted to replacing the liquid electrolytes with polymer electrolytes [6-18]. However, solid polymer electrolytes show low ionic conductivity at ambient temperatures and poor electrolyte-electrode interfacial contacts, resulting in low conversion efficiency. On the other hand, gel polymer electrolytes

*E-mail address: dongwonkim@hanyang.ac.kr DOI: https://doi.org/10.5229/JECST.2017.8.3.257 that exhibit high ionic conductivity improve the conversion efficiency of DSSCs. However, in gel polymer electrolytes, both cations and anions are mobile, thereby polarizing the electrolyte and increasing the resistance of $\mathrm{I}^{-} / \mathrm{I}_{3}^{-}$ions [19]. Accordingly, it is desirable to use a single-ion-conducting gel polymer electrolyte in which the cations are immobilized to the polymer backbone and the anions $\left(\mathrm{I}^{-}\right)$are highly mobile. Among the single-ion-conducting electrolytes, polymeric ionic liquids represent an important class of polymer electrolytes in which the cationic or anionic centers are confined to the repeating unit [20-29]. Although polymeric ionic liquid-based electrolytes have been extensively studied, their ionic conductivities are too low for practical applications at ambient temperature [30].

In this work, we report the synthesis and electrochemical characteristics of gel polymer electrolytes based on a polymeric ionic liquid, poly(1-methyl 3(2-acryloyloxypropyl) imidazolium iodide) (PMAPII), in which iodide ions can easily migrate, while the imidazolium cations are immobilized to the polymer backbone. Gel polymer electrolytes with 
high conductivity and enhanced stability were prepared by blending iodine, 4-tert-butylpyridine (TBP), $\gamma$-butyrolactone (GBL), and PMAPII. PMAPII played an important role in not only increasing the concentration of $\mathrm{I}^{-}$ions but also forming the stable gel polymer electrolyte. No additional iodide salts such as LiI were used to form the redox couple $\left(\mathrm{I}^{-} / \mathrm{I}_{3}^{-}\right)$ in the gel polymer electrolytes. The photovoltaic performance of quasi-solid-state DSSCs assembled with these gel polymer electrolytes was investigated and compared to that of the liquid-electrolyte-based DSSC. Our results demonstrated that the DSSC employing the PMAPII-based gel polymer electrolytes exhibited a relatively high conversion efficiency of $7.67 \%$ and good long-term stability.

\section{Experimental}

\subsection{Synthesis of PMAPII}

PMAPII was synthesized in three steps (Fig. 1), as previously described in detail for the synthesis of other similar polymeric ionic liquid systems [31-33]. First, 3-iodo-1-propanol (Aldrich) dissolved in tetrahydrofuran (THF) with a catalytic amount of triethylamine was fed into a glass reactor. A solution with a slight molar excess of acryloyl chloride (Aldrich) in THF was added dropwise to the reactor over a period of $1 \mathrm{~h}$ under an $\mathrm{N}_{2}$ atmosphere at $0^{\circ} \mathrm{C}$. After the entire solution was added, the solution was vigorously stirred for another $24 \mathrm{~h}$. The triethylamine salt was filtered off, and the product (3-iodopropyl acrylate) was obtained by removing the THF using a rotary vacuum evaporator. For the quaternization reaction, a mixture of the as-prepared 3-iodopropyl acrylate and n-methylimidazole (Aldrich) was dissolved in ethanol and stirred at $45^{\circ} \mathrm{C}$ for $24 \mathrm{~h}$ under an $\mathrm{N}_{2}$ atmosphere. The product was purified by precipitation with diethyl ether to obtain 1-methyl 3(2-acryloyloxypropyl) imidazolium iodide (MAPII). The obtained MAPII monomer was polymerized with azobisisobutyronitrile (AIBN) as a free-radical initiator in dimethylsulfoxide (DMSO) at $80^{\circ} \mathrm{C}$ for $12 \mathrm{~h}$ under an $\mathrm{N}_{2}$ atmosphere. After polymerization, the resulting solution was added dropwise into a large excess of diethyl ether. The polymer was washed successively with diethyl ether to remove any impurities such as residual monomer and initiator. The polymer was then dried in a vacuum oven at $120^{\circ} \mathrm{C}$ for $24 \mathrm{~h}$. The obtained polymeric ionic liquid (PMAPII) was a flexible solid. The chemical structures of MAPII and PMAPII were confirmed by ${ }^{1} \mathrm{H}$ NMR spectra using a VARIAN (Mercury 300) NMR spectrometer with a DMSO-d $_{6}$ solvent.

\subsection{Cell assembly}

To prepare the gel polymer electrolyte, various amounts (12, 14, 16, 18, 20 wt.\%) of PMAPII were separately added to the liquid electrolyte. The liquid electrolyte used in this study was a solution of $0.05 \mathrm{M} \mathrm{I}_{2}$ and $0.05 \mathrm{M}$ TBP dissolved in GBL. A nanocrystalline $\mathrm{TiO}_{2}$ paste (Ti-Nanoxide T20/SP, Solaronix) was cast onto a fluorine-doped tin oxide (FTO)-coated glass using a doctor blade, which was sintered at $450^{\circ} \mathrm{C}$ for $30 \mathrm{~min}$. Then, this electrode was sensitized overnight with a cis-diisothiocyanatobis(2,2'-bipyridyl-4,4'-dicarboxylato) ruthenium (II)

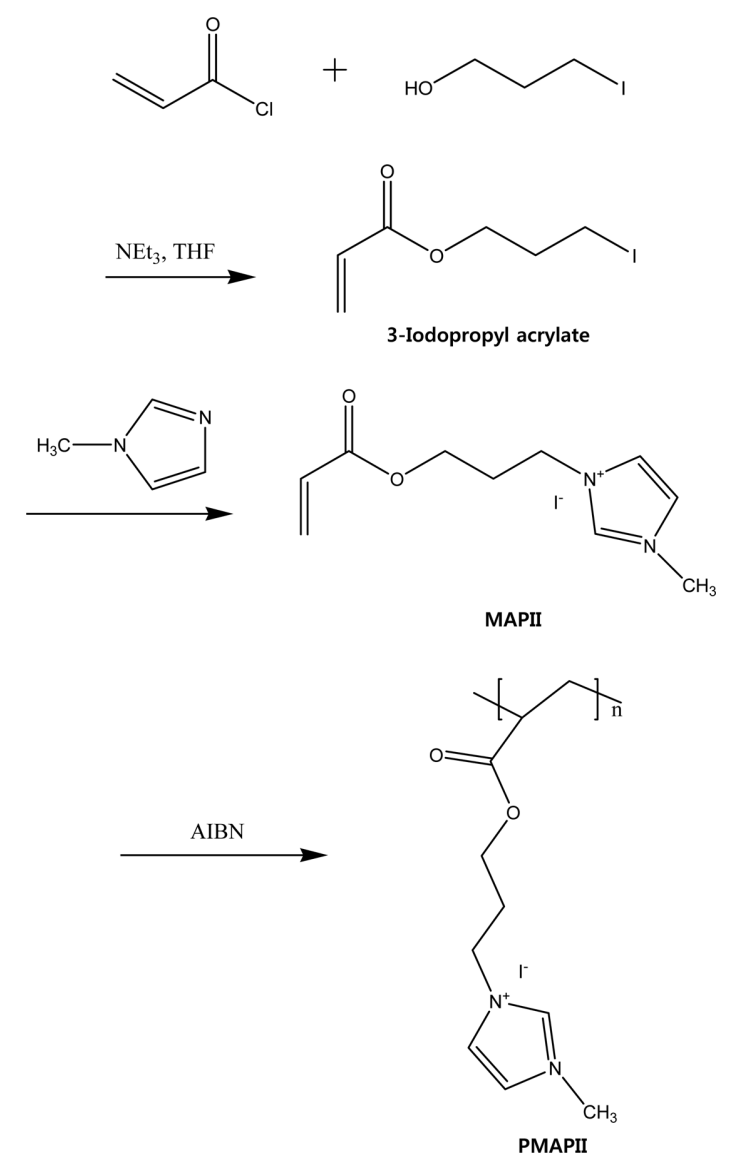

Fig. 1. Synthetic scheme of poly(1-methyl 3-(2acryloyloxypropyl) imidazolium iodide). 
bis(tetrabutyl ammonium) (Ruthenium 535 bis-TBA, Solaronix) dye solution. A Pt counter electrode was prepared by spin-coating $0.01 \mathrm{M} \mathrm{H}_{2} \mathrm{PtCl}_{6}$ in isopropanol onto FTO glass and sintering at $450^{\circ} \mathrm{C}$ for 30 min. The gel polymer electrolyte was directly cast onto the $\mathrm{TiO}_{2}$ electrode. The cell was then fabricated by sealing the $\mathrm{TiO}_{2}$ electrode and Pt counter electrode together using a hot melting film. The thickness of the gel polymer layer between two electrodes was about $15 \mu \mathrm{m}$, and the cell geometry was $0.5 \times 0.5 \mathrm{~cm}^{2}$.

\subsection{Measurements}

The ionic conductivity of the gel polymer electrolyte was measured by electrochemical impedance spectroscopy using a Zahner Electrik IM6 impedance analyzer over a frequency range of $10 \mathrm{~Hz}$ to $100 \mathrm{kHz}$ with an amplitude of $10 \mathrm{mV}$. A two-electrode electrochemical cell consisting of a gel polymer electrolyte sandwiched between two identical Pt electrodes was used to measure the diffusion coefficient of the triiodide ion from the diffusion-limited current measurements [34,35]. The diffusion-limited current density was determined by cyclic voltammetry at a scan rate of $5 \mathrm{mV} \mathrm{s}^{-1}$. The surface and cross-sectional morphologies of the $\mathrm{TiO}_{2}$ electrodes were examined using a field emission scanning electron microscope (FE-SEM, JEOL, JSM-6710F). The photovoltaic performance of the DSSCs was evaluated using a xenon light source $\left(100 \mathrm{~mW} \mathrm{~cm}^{-2}\right)$ with an AM 1.5 filter in a solar simulator. The light intensity was calibrated with a NREL-calibrated Si solar cell (PV Measurements Inc.). A black mask with an aperture of $0.25 \mathrm{~cm}^{2}$ was placed over the cells during irradiation, and anti-reflection glass was placed on the front glass cover of the cells. Each performance measurement was repeated with at least five cells to obtain reproducible results. In order to evaluate the long-term stability behavior of the DSSCs, the cells were kept in the dark and only irradiated during measurements. The AC impedance of the DSSCs was measured using an impedance analyzer over a frequency range of $10 \mathrm{mHz}$ to $100 \mathrm{kHz}$ at open circuit under 1 Sun illumination. The applied bias voltage and ac amplitude were set to the open-circuit voltage and $10 \mathrm{mV}$, respectively. The impedance spectra were analyzed using an equivalent circuit model to interpret the characteristics of the DSSCs [36-38].

\section{Results and Discussion}

Fig. 2 shows the ${ }^{1} \mathrm{H}$ NMR spectra of MAPII and PMAPII. The vinyl proton peaks $\left(\mathrm{CH}_{2}=\mathrm{CH}-\right)$ in MAPII were observed in the range of 6.0 to $6.5 \mathrm{ppm}$, as shown in Fig. 2(a). After polymerization of the MAPII monomer, the peaks clearly disappeared, and new proton peaks $\left(-\mathrm{CH}_{2}-\mathrm{CH}-\right)$ corresponding to the polymer backbone were observed around $3.36 \mathrm{ppm}$, as shown in Fig. 2(b), indicating that the MAPII monomer was polymerized to PMAPII. The protons in the imidazole ring $\left(-\mathrm{CH}_{\text {imidazole }}-\right)$ appeared at 7.83 , 7.92 and $9.30 \mathrm{ppm}$, as reported previously [33]. The methylene protons $\left(-\mathrm{CH}_{2}-\right)$ of the side acryloyloxypropyl unit were observed at 2.16, 4.17 and 4.32 ppm. The ${ }^{1} \mathrm{H}$ NMR spectrum of PMAPII was consistent with the expected chemical structure.

Fig. 3 shows the diffusion coefficients of $\mathrm{I}_{3}{ }^{-}$and ionic conductivities of the gel polymer electrolytes as a function of the PMAPII content. As expected, the diffusion coefficient of the $\mathrm{I}_{3}{ }^{-}$ion in the gel polymer electrolyte decreases with increasing PMAPII con-

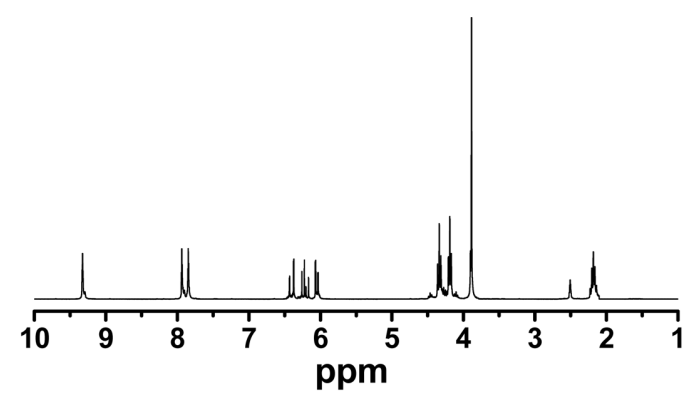

(a) MAPII



(b) PMAPII

Fig. 2. ${ }^{1} \mathrm{H}$ NMR spectra of (a) MAPII and (b) PMAPII in DMSO- $\mathrm{d}_{6}$. 


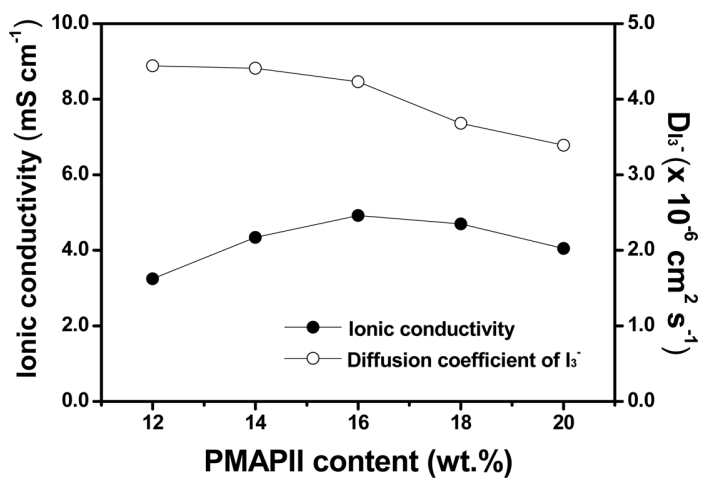

Fig. 3. Diffusion coefficients of $\mathrm{I}_{3}{ }^{-}$and ionic conductivities of gel polymer electrolytes as a function of the PMAPII content.

tent. On the other hand, the ionic conductivity first increases to a maximum value and then decreases with the further increasing PMAPII content. As mentioned earlier, no iodide salt was added to the gel polymer electrolyte, and thus, PMAPII acted as the iodide source in the redox couple $\left(\mathrm{I}^{-} / \mathrm{I}_{3}{ }^{-}\right)$. Accordingly, the initial increase in ionic conductivity with the increasing PMAPII content can be ascribed to the increase in the number of free ions dissociating from PMAPII in the gel polymer electrolyte. On the other hand, the ionic mobility eventually decreases with the increasing PMAPII content due to the increase in the number of ion-dipole interactions between PMAPII and GBL. Thus, the decrease in ionic conductivity with more than 16 wt.\% PMAPII was attributed to the decrease in ionic mobility with the increasing PMAPII content. At 16 wt.\% PMAPII, the ionic conductivity and diffusion coefficients were as high as $4.9 \times 10^{-3} \mathrm{~S} \mathrm{~cm}^{-1}$ and $4.2 \times 10^{-6} \mathrm{~cm}^{2} \mathrm{~s}^{-1}$ at room temperature, respectively.

The surface morphologies of the $\mathrm{TiO}_{2}$ electrode before and after casting the gel polymer electrolyte with 16 wt.\% PMAPII are shown in Fig. 4(a) and (b), respectively. As shown in Fig. 4(a), the $\mathrm{TiO}_{2}$ nanoparticles were well distributed, and the electrode had a highly porous structure in which the nanoparticles were bonded together through sintering. After casting the gel polymer electrolyte onto the $\mathrm{TiO}_{2}$ electrode, the surface became smoother due to the full coverage of gel polymer electrolyte (Fig. 4(b)). Moreover, the gel polymer electrolyte penetrated into the pores of the $\mathrm{TiO}_{2}$ electrode, as shown in the cross-sectional image of the $\mathrm{TiO}_{2}$
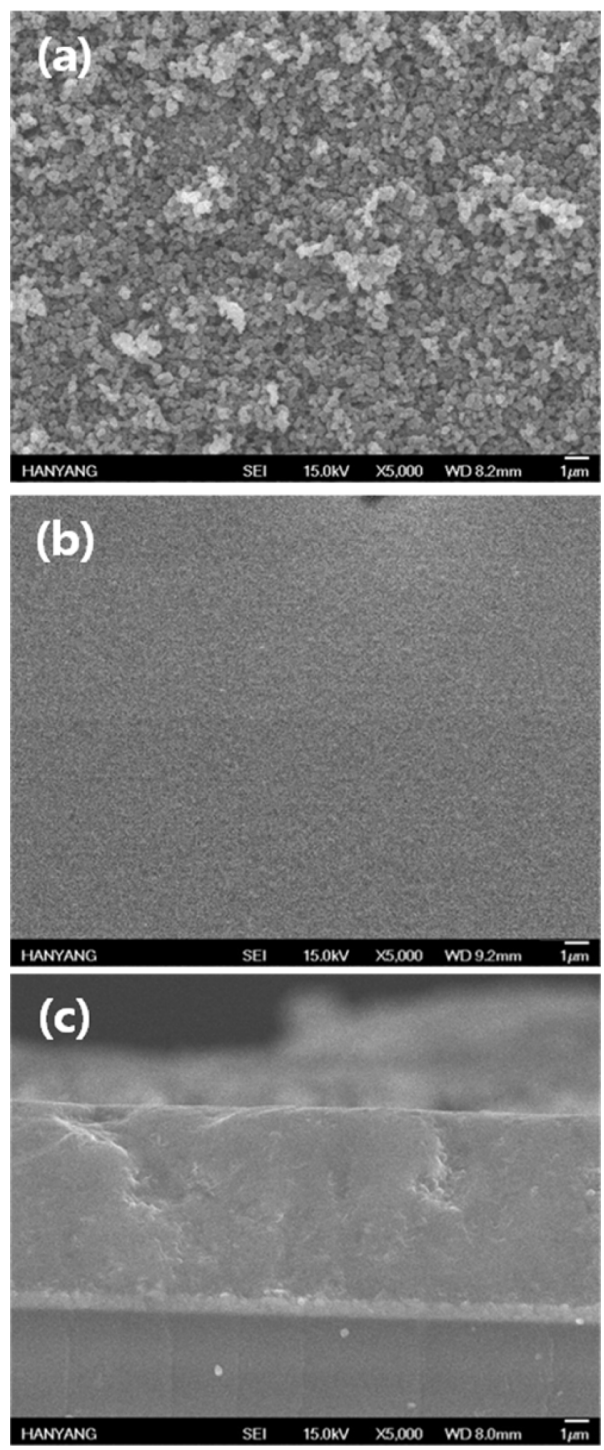

Fig. 4. Surface SEM images of a $\mathrm{TiO}_{2}$ electrode (a) before and (b) after casting the gel polymer electrolyte and (c) cross-sectional SEM image of the $\mathrm{TiO}_{2}$ electrode.

electrode (Fig. 4(c)), which enhanced the interfacial contact between the $\mathrm{TiO}_{2}$ electrode and the gel polymer electrolyte.

The photovoltaic performance of the DSSCs assembled with PMAPII-based gel polymer electrolytes was evaluated. Fig. 5 shows the photocurrent density-voltage curves of the DSSCs with gel polymer electrolytes containing different amounts of PMAPII. The photocurrent density-voltage curve of 
the DSSC prepared with a liquid electrolyte is also shown for comparison. It should be noted that $0.5 \mathrm{M}$ LiI was added into the liquid electrolyte as an iodide source. Table 1 summarizes the photovoltaic performance of DSSCs with the liquid and gel polymer electrolytes. The $\mathrm{V}_{\mathrm{oc}}$ values of the DSSCs assembled with the gel polymer electrolyte were higher than that of the liquid-electrolyte-based DSSC. The presence of small $\mathrm{Li}^{+}$cations in the liquid electrolyte may cause the band edges to shift to a more positive potential, because the $\mathrm{Li}^{+}$cations adsorbed on the $\mathrm{TiO}_{2}$ surface are likely to induce a potential drop across the Helmholtz layer. This potential drop results in a decrease in the $\mathrm{V}_{\text {oc }}$ of DSSCs based on a liquid electrolyte containing lithium iodide [39]. The increase in the $\mathrm{V}_{\mathrm{oc}}$ in the gel-electrolyte DSSCs is also ascribed to the suppression of charge recombination at the $\mathrm{TiO}_{2} /$ electrolyte interface. Electrons injected into $\mathrm{TiO}_{2}$ are well known to recombine with $\mathrm{I}_{3}{ }^{-}$in the electrolyte. Since the $\mathrm{I}_{3}{ }^{-}$ions in the gel poly-

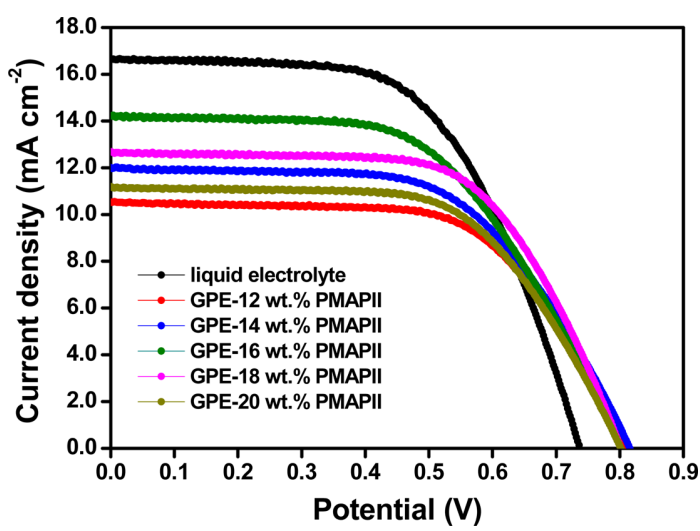

Fig. 5. Photocurrent density-voltage curves of the DSSCs with the liquid electrolyte and the gel polymer electrolytes containing different amounts of PMAPII at $100 \mathrm{~mW} \mathrm{~cm}$. mer electrolyte have fewer chances to interact with electrons in the $\mathrm{TiO}_{2}$, the recombination reaction can be hindered, resulting in an increase in the $\mathrm{V}_{\text {oc }}$ in the DSSCs with gel polymer electrolyte and little dependence of the $\mathrm{V}_{\text {oc }}$ on the PMAPII content [40,41]. On the other hand, the short circuit current densities $\left(\mathrm{J}_{\mathrm{sc}}\right)$ of the gel-electrolyte DSSCs are lower than that of the liquid-electrolyte DSSC. The gelation of the liquid electrolyte due to the addition of PMAPII lowered the ionic conductivity and increased the interfacial resistance at the electrodes, which resulted in a decrease in the $\mathrm{J}_{\mathrm{sc}}$. Interestingly, the $\mathrm{J}_{\mathrm{sc}}$ of the gel-electrolyte DSSC increased with a content of PMAPII up to $16 \mathrm{wt} . \%$ and decreased with further addition. The low $\mathrm{J}_{\mathrm{sc}}$ at low PMAPII content was related to the insufficient concentration of $\mathrm{I}^{-}$ions and hence the low rate for the charge transfer reaction of the redox couple $\left(\mathrm{I}^{-} / \mathrm{I}_{3}{ }^{-}\right)$at the electrodes. A decrease in the $\mathrm{J}_{\mathrm{sc}}$ beyond 16 wt.\% PMAPII can be attributed to the decrease in the ionic mobility, as explained earlier. These results suggest that the concentration of iodide ions and the ionic mobility should be balanced to achieve the highest conversion efficiency. The quasisolid-state DSSC assembled with the $16 \mathrm{wt} . \%$ PMAPII gel polymer electrolyte exhibited a relatively high initial conversion efficiency of $6.45 \%$ at $100 \mathrm{~mW} \mathrm{~cm}^{-2}$.

In order to investigate the impedance behavior of the liquid- and gel-electrolyte DSSCs, the ac impedance of the cells was measured, and the results are shown in Fig. 6. These spectra can be analyzed by using the equivalent circuit given in the inset of the figure [36-38]. All the spectra exhibit three semicircles, which can be assigned to the electrochemical reaction at the $P t$ counter electrode $\left(\mathrm{R}_{\mathrm{ct} 1}\right)$, the charge transfer reaction at the $\mathrm{TiO}_{2}$ electrode $\left(\mathrm{R}_{\mathrm{ct} 2}\right)$, and the Warburg diffusion process of $\mathrm{I}^{-} / \mathrm{I}_{3}^{-}\left(\mathrm{R}_{\text {diff }}\right)$. The resis-

Table 1. Photovoltaic performance of DSSCs assembled with liquid and gel polymer electrolytes (GPEs).

\begin{tabular}{ccccc}
\hline \hline Electrolyte & $\mathrm{V}_{\mathrm{oc}}(\mathrm{V})$ & $\begin{array}{c}\mathrm{J}_{\mathrm{sc}} \\
\left(\mathrm{mA} \mathrm{cm}^{-2}\right)\end{array}$ & $\begin{array}{c}\text { Fill } \\
\text { factor }\end{array}$ & $\begin{array}{c}\text { Conversion } \\
\text { efficiency }(\%)\end{array}$ \\
\hline Liquid electrolyte & 0.74 & 16.62 & 0.59 & 7.20 \\
GPE-12 wt.\% PMAPII & 0.81 & 10.53 & 0.61 & 5.22 \\
GPE-14 wt.\% PMAPII & 0.82 & 12.00 & 0.59 & 5.76 \\
GPE-16 wt.\% PMAPII & 0.80 & 14.20 & 0.57 & 6.45 \\
GPE-18 wt.\% PMAPII & 0.80 & 12.69 & 11.19 & 0.61 \\
GPE-20 wt.\% PMAPII & 0.80 & & 6.34 \\
\hline
\end{tabular}


tances estimated using the equivalent circuit are given in Table 2. The electrolyte resistance $\left(\mathrm{R}_{\mathrm{el}}\right)$ is lowest in the DSSC assembled with liquid electrolyte. In the gel-electrolyte DSSCs, the electrolyte resistance decreased with the PMAPII content up to $16 \mathrm{wt} . \%$ and then increased with higher contents, which is consistent with the ionic conductivity results in Fig. 3. When the content of PMAPII was less than 16 wt. $\%$, the observed interfacial resistances $\left(\mathrm{R}_{\mathrm{ct} 1}\right.$ and $\mathrm{R}_{\mathrm{ct} 2}$ ) were high, which may be due to the lack of ions involved in the redox couple $\left(\mathrm{I}^{-} / \mathrm{I}_{3}{ }^{-}\right)$. The Warburg diffusion resistance $\left(\mathrm{R}_{\text {diff }}\right)$ of the redox couple increased with the PMAPII content, which can be ascribed to the decrease in ionic mobility. This result indicated that adding the appropriate amount of PMAPII containing iodide ions not only decreases the electrolyte resistance but also improves the charge transfer reaction at both the $\mathrm{TiO}_{2}$ electrode and Pt counter electrode, resulting in a high conversion efficiency, which is consistent with the photovoltaic performance of the

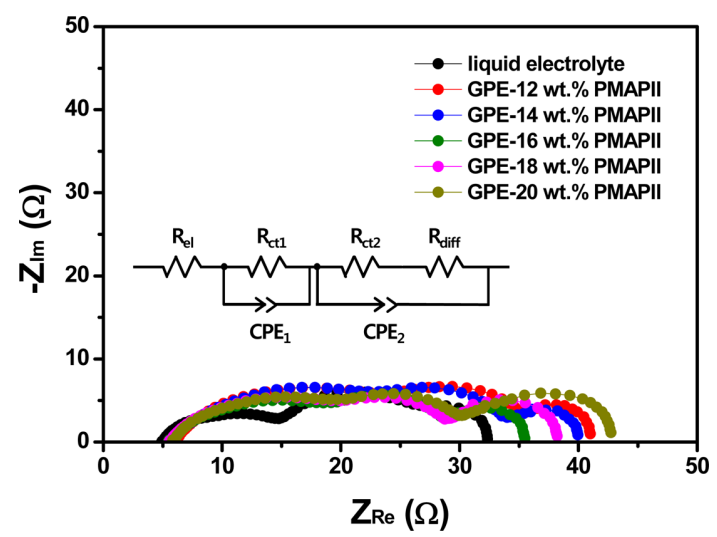

Fig. 6. AC impedance spectra of DSSCs assembled with liquid and gel polymer electrolytes recorded at $100 \mathrm{~mW}$ $\mathrm{cm}^{-2}$ under open circuit conditions.
DSSCs shown in Fig. 5.

The long-term durability of a quasi-solid-state gelelectrolyte DSSC was evaluated and compared to that of the liquid-electrolyte-based DSSC. Fig. 7 compares the variation in the conversion efficiency of the liquid-electrolyte DSSC with that of the 16 wt.\% PMAPII gel-electrolyte DSSCs as a function of storage time. As shown in the figure, the longterm stability of the gel-electrolyte DSSC was obviously superior to that of the liquid-electrolyte DSSC. The conversion efficiency in the liquid-electrolyte DSSC decayed continuously with time over the investigated period. After 30 days, the cell lost $30 \%$ of its initial conversion efficiency due to the leakage or evaporation of the liquid electrolyte. On the other hand, the conversion efficiency of the quasi-solidstate gel-polymer DSSC slightly increased and then remained almost constant. Notably, its conversion efficiency increased from its initial efficiency of

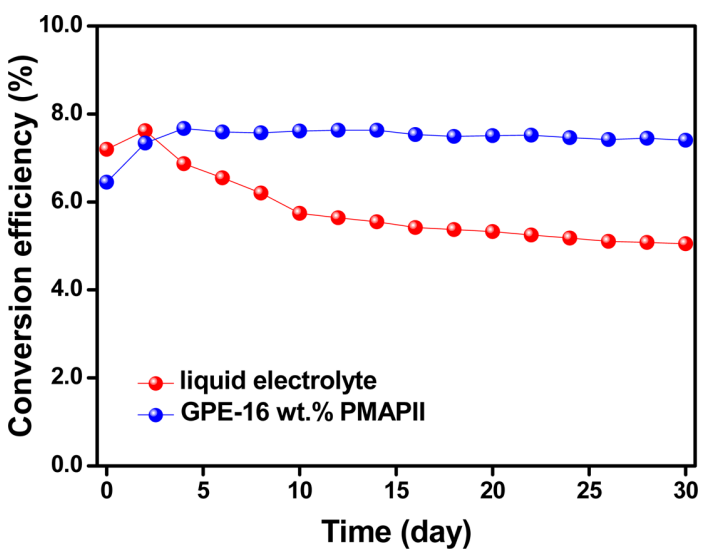

Fig. 7. Variation in the conversion efficiency of DSSCs assembled with the liquid electrolyte and the gel polymer electrolyte containing $16 \mathrm{wt} \%$ PMAPII as a function of time.

Table 2. $R_{\mathrm{el}}, \mathrm{R}_{\mathrm{ct} 1}, \mathrm{R}_{\mathrm{ct} 2}$ and $\mathrm{R}_{\text {diff }}$ estimated from the electrochemical impedance data and equivalent circuit.

\begin{tabular}{ccccc}
\hline \hline Electrolyte & $\mathrm{R}_{\mathrm{el}}(\Omega)$ & $\mathrm{R}_{\mathrm{ct} 1}(\Omega)$ & $\mathrm{R}_{\mathrm{ct} 2}(\Omega)$ & $\mathrm{R}_{\mathrm{diff}}(\Omega)$ \\
\hline Liquid electrolyte & 4.9 & 7.9 & 12.2 & 7.7 \\
GPE-12 wt.\% PMAPII & 6.0 & 13.1 & 13.6 & 8.2 \\
GPE-14 wt.\% PMAPII & 5.7 & 12.6 & 13.1 & 8.5 \\
GPE-16 wt.\% PMAPII & 5.3 & 10.1 & 11.1 & 9.3 \\
GPE-18 wt.\% PMAPII & 5.5 & 10.8 & 11.3 & 10.1 \\
GPE-20 wt.\% PMAPII & 5.8 & 12.7 & 12.4 & 11.8 \\
\hline
\end{tabular}


$6.45 \%$ to $7.67 \%$ after 4 days, which is higher than the initial conversion efficiency of the liquid-electrolytebased DSSC (7.20\%). The initial increase in the conversion efficiency can be ascribed to the improvement in the interfacial contact between the $\mathrm{TiO}_{2}$ electrode and electrolyte with time. When the gel polymer electrolyte was employed, the organic solvent was well encapsulated in the quasi-solid-state DSSC due to the strong ion-dipole interactions between PMAPII and GBL. The adhesive property of the gel polymer electrolyte also promoted the interfacial contact between the dye-adsorbed $\mathrm{TiO}_{2}$ electrode and the platinum counter electrode, providing the DSSC with more stable performance than that of the liquid-electrolyte DSSC.

\section{Conclusions}

A polymeric ionic liquid, PMAPII, was synthesized and used as both a gelling agent and iodide source for quasi-solid-state DSSCs. PMAPII played an important role in not only increasing the concentration of $\mathrm{I}^{-}$ions but also forming a stable gel polymer electrolyte. The content of PMAPII was optimized to $16 \mathrm{wt} . \%$ to strike a balance between the iodide ion concentration and the ionic mobility to achieve the highest conversion efficiency. The quasi-solid-state DSSC assembled with the 16 wt.\% PMAPII gel polymer electrolyte exhibited a relatively high conversion efficiency of $7.67 \%$ at $100 \mathrm{~mW} \mathrm{~cm}^{-2}$ and better stability than the DSSC with the liquid electrolyte.

\section{Acknowledgement}

This work was supported by the Technology Innovation Program funded by the Ministry of Trade, Industry and Energy (MOTIE, Korea) (10069215) and the Basic Science Research Program of the National Research Foundation of Korea (NRF), funded by the Ministry of Science, ICT, and Future Planning (2016R1A4A1012224).

\section{References}

[1] B. O'Reagen and M. Gratzel, Nature, 1991, 353(6346), 737-740.

[2] A. Hagfeldt, G. Boschloo, L. Sun, L. Kloo and H. Pettersson, Chem. Rev.,2010, 110(11), 6595-666.

[3] A. Yella, H.W. Lee, H.N. Tsao, C. Yi, A.K. Chandiran, M. Nazeeruddin, E.W.G. Diau, C.Y. Yeh, S.M. Zakeeruddin and M. Gratzel, Science, 2011, 334(6056), 629-634.

[4] Md. M. Rahman, H.-S. Son, S.-S. Lim, K.-H. Chung and J.-J. Lee, J. Electrochem. Sci. and Tech., 2011,2(2), 110-115.

[5] J. Kwon and J.H. Park, J. Electrochem. Sci. and Tech., 2013, 4(3), 89-92.

[6] P. Wang, S.M. Zakeeruddin, J.E. Moser, M.K. Nazeeruddin, T. Sekiguchi and M. Gratzel, Nat. Mater., 2003, 2(6), 402.

[7] D.-W. Kim, Y.-B. Jeong, S.-H. Kim, D.-Y. Lee and J.-S. Song, J. Power Sources, 2005, 149, 112-116.

[8] B. Li, L. Wang, B. Kang, P. Wang and Y. Qiu, Sol. Energy Mater. Sol. Cells, 2006, 90(5), 549-573.

[9] M. Li, S. Feng, S. Fang, X. Xiao, X. Li, X. Zhou and Y. Lin, Electrochim. Acta, 2007, 52(14), 4858-4863.

[10] Z. Huo, S. Dai, K. Wang, F. Kong, C. Zhang, X. Pan and X. Fang, Sol. Energy Mater. Sol. Cells, 2007, 91(20), 1959-1965.

[11] J.N. de Freitas, A.F. Nogueira and M.-A. De Paoli, J. Mater. Chem., 2009, 19(30), 5279-5294.

[12] S.J. Lim, Y.J. Choi, K.S. Song and D.-W. Kim, Electrochem. Commun., 2011, 13(11), 1284-1287.

[13] S.J. Lim, Y.S. Kang and D.-W. Kim, Electrochim. Acta, 2011, 56(5), 2031-2035.

[14] M. Wang, X. Pan, X. Fang, L. Guo, C. Zhang, Y. Huang, Z. Huo and S. Dai, J. Power Sources, 2011, 196(13), 5784-5791.

[15] X. Huang, Y. Liu, J. Deng, B. Yi, X. Yu, P. Shen and S. Tan, Electrochim. Acta, 2012, 80, 219-226.

[16] Y.-C. Wang, K.-H. Huang, R.-X. Dong, C.-T. Liu, C.-C. Wang, K.-C. Ho and J.-J. Lin, J. Mater. Chem., 2012, 22(14), 6982-6989,

[17] C. Wang, L. Wang, Y. Shi, H. Zhang and T. Ma, Electrochim. Acta, 2013, 91, 302-306.

[18] L.-Y. Chang, C.-P. Lee, R. Vittal, J.-J. Lin and K.-C. Ho, J. Mater. Chem. A, 2013, 1(9), 3055-3060.

[19] B.K. Mandal, C.J. Walsh, T. Sooksimuang, S.J. Behroozi, S.G. Kim and Y.T. Kim, Chem. Mater, 2000, 12(1), 6-8

[20] J. Wu, S. Hao, Z. Lan, J. Lin, M. Huang, Y. Huang, P. Li, S. Yin and T. Sato, J. Am. Chem. Soc., 2008, 130(35), 11568-111569.

[21] Y. Jiang, Y.L. Cao, P. Liu, J.F. Qian and H.X.Yang, Electrochim. Acta, 2010, 55(22), 6415-6419.

[22] E. Azaceta, R. Marcilla, A. Sanchez-Diaz, E. Palomares and D. Mecerreyes, Electrochim. Acta, 2010, 56(1), $42-46$.

[23] R. Kawano, T. Katakabe, H. Shimosawa, M.K. Nazeeruddin, M. Gratzel, H. Matsui, T. Kitamura, N. Tanabe and M. Watanabe, Phys. Chem. Chem. Phys., 2010, 12(8), 1916-1921.

[24] D. Mecerreyes, Prog. Polym. Sci., 2011, 36(12), $1629-$ 1648.

[25] W.S. Chi, J.K. Koh, S.H. Ahn, J.S. Shin, H. Ahn, D.Y. Ryu and J.H. Kim, Electrochem. Commun., 2011, 13(12), 1349-1352.

[26] G. Wang, L. Wang, S. Zhuo, S. Fang and Y. Lin, Chem. 
Commun., 2011, 47(9), 2700-2702.

[27] X. Chen, J. Zhao, J. Zhang, L. Qiu, D. Xu, H. Zhang, X. Han, B. Sun, G. Fu, Y. Zhang and F. Yan, J. Mater. Chem., 2012, 22(34), 18018-18024.

[28] M. Dobbelin, I. Azcune, M. Bedu, A.R. de Luzuriaga, A. Genua, V. Jovanovski, G. Cabanero and I. Odriozola, Chem. Mater., 2012, 24(9), 1583-1590.

[29] Y.-S. Lee and D.-W. Kim, Electrochim. Acta, 2013, 106, 460-464.

[30] M. Hirao, K. Ito and H. Ohno, Electrochim. Acta, 2000, 45(8), 1291-1294.

[31] M. Yoshizawa and H. Ohno, Electrochim. Acta, 2001, 46(10), 1723-1728.

[32] W. Ogihara, S. Washiro, H. Nakajima and H. Ohno, Electrochim. Acta, 2006, 51(13), 2614-2619.

[33] B. Yu, F. Zhou, C. Wang and W. Liu, Eur. Polym. J, 2007, 43(6), 2699-2707.

[34] A. Hauch and A. Georg, Electrochim. Acta, 2001, 46(22), 3457-3466.
[35] M. Zistler, P. Wachter, P. Wasserscheid, D. Gerhard, A. Hinsch, R. Sastrawan and H.J. Gores, Electrochim. Acta, 2006, 52(1), 161-169.

[36] C. Longo, J. Freitas and M.A. De Paoli, J. Photochem. Photobiol. A: Chem., 2003, 159(1), 33-39.

[37] Q. Wang, J.E. Moser and M. Gratzel, J. Phys. Chem. B, 2005, 109(31), 14945-14953.

[38] K.-M. Lee, V. Suryanarayanan and K.-C. Ho, J. Power Sources, 2008, 185(2), 1605-1612.

[39] N.G. Park, S.H. Chang, J.van de Lagemaat, K.J. Kim and A.J. Frank, Bull. Korean Chem. Soc., 2000, 21(10), 985-988.

[40] X. Zhang, H. Yang, H.M. Xiong, F.Y. Li and Y.Y. Xia, J. Power Sources, 2006, 160(2), 1451-1455.

[41] T.C. Wei, C.C. Wan and Y.Y. Wang, Sol. Energy Mater. Sol. Cells, 2007, 91(20), 1892-1987. 